\title{
A casa, o jardim e a rua no Brasil do século XIX
}

Solange de Aragão*

\begin{abstract}
Resumo: Este trabalho tem como ponto de partida a obra Sobrados e mucambos de Gilberto Freyre, como fonte documental os relatos dos viajantes, e como objeto de estudo a casa, o jardim brasileiro e a rua do século XIX. Trata das transformações pelas quais passaram a arquitetura e esses espaços livres ao longo do oitocentismo, contrapondo os sobrados de dois, três e quatro pavimentos, erguidos no alinhamento dos lotes, sem recuo frontal ou lateral, com seu "jardim-horta-pomar" situado no recuo posterior, aos sobrados de fins do século, projetados sob clara influência européia, com jardins ornamentais dissociados das hortas e pomares, dispostos no recuo frontal ou lateral. Trata, ainda, das alterações da rua: o processo de calçamento do leito carroçável e dos passeios junto às construções, o início da iluminação pública e os primórdios da arborização urbana no Brasil, ressaltando a inter-relação entre as mudanças internas e externas ao lote urbano, que iriam contribuir significativamente para a transformação da paisagem da cidade brasileira do período.
\end{abstract}

Palavras-chave: casa, rua, jardim.

Abstract: This paper has as its starting point the work The mansions and the shanties, by Gilberto Freyre, as its source material some voyager's writings, and as its object of study the house, the Brazilian garden, and the street of the 19th century. It deals with some transformation by which architecture and open spaces passed throughout this century, and compares those two, three and four-storey houses, built up in the alignment of the lot and in its lateral limits - their "orchard-ornamental-vegetable garden" in the backyard - with those two-storey houses from the last decades of the 19th century, under European influence, with their ornamental garden separeted from orchard and vegetable gardens, situated then in the front yard and beside the house. It also deals with some transformation of urban streets: their being paved, the creation of sidewalks, the beginnig of street lighting, and the planting of trees along the streets, emphasizing the relation between internal and external changes of the urban lot, which would contribute significantly to transformation of Brazilian urban landscape at the 19 th century.

Key-words: house, street, garden.

A residência urbana e semi-urbana do Brasil no início do século XIX parecia simples e rudimentar ao olhar europeu. Na cidade, era a casa térrea, de porta e janela, com sala, alcovas e varanda, ou o sobrado, de dois, três, quatro pavimentos, com loja, armazém ou depósito no térreo, escritório, salas, alcovas e cozinha nos andares superiores. Era a casa de taipa de pilão, a casa de pedra e cal, a casa de "granito miúdo", construída sempre com os materiais

\footnotetext{
* Arquiteta, Urbanista, Mestre e Doutora pela FAUUSP. Pós-doutoranda pela Faculdade de Filosofia, Letras e Ciências Humanas da USP. Departamento de História. Orientadora: Profa. Dra. Raquel Glezer. Apoio: Fundação de Amparo à Pesquisa do Estado de São Paulo (FAPESP).
} 
disponíveis no entorno; a casa com telhados de duas ou de quatro águas, com telhas do tipo capa-canal e beirais a proteger as paredes das águas da chuva; a casa dos muxarabis ou gelosias, que foram banidos da fachada principal das residências logo após a chegada da Corte ao Rio de Janeiro. Era a casa erguida no alinhamento, sem recuo frontal ou lateral, a conformar ruas estreitas e tortuosas; a casa do "jardim-horta-pomar", onde plantas ornamentais apareciam misturadas a hortaliças e árvores frutíferas - um jardim que ficava no recuo posterior, atrás dos muros, longe do olhar dos transeuntes.

A meio caminho do campo, a residência semi-urbana era quase sempre térrea (ou assobradada) e construída, da mesma forma, com os materiais disponíveis no entorno. Contava com horta, pomar e jardim, situando-se na maioria das vezes nas proximidades de um rio, riacho ou córrego d'água. Com frutas, verduras, água e capim para os animais, a residência semi-urbana compunha uma estrutura mais auto-suficiente que a urbana. Os cômodos internos eram melhor ventilados e iluminados, uma vez que a construção estava isolada no terreno. Essas casas compunham uma paisagem mais horizontal, com as construções esparsas, cercadas pelo verde.

Com a chegada da Corte ao Rio de Janeiro e a difusão do neoclássico pela Missão Artística Francesa, a residência urbana e semi-urbana do Brasil começa a se transformar. Muda a casa, altera-se o jardim, acompanhando as modificações do gosto, dos hábitos e dos costumes dos brasileiros em um processo que Gilberto Freyre denominou de "reeuropeização"

No interior do lote, para que os dormitórios recebessem iluminação e fossem melhor ventilados, estabeleceu-se o recuo de um ou de ambos os lados da construção; para garantir maior privacidade aos moradores, a casa afastou-se da rua, por meio do estabelecimento do recuo frontal - ideal para a implantação do jardim em frente à residência como elemento de valorização da arquitetura. A passagem do jardim dos fundos para o jardim lateral ou frontal levou também a alterações na concepção desse espaço livre, que deixou de estar misturado às hortas e pomares, tornando-se fundamentalmente ornamental.

$\mathrm{Na}$ fachada das novas residências ficou evidente a influência européia, em um primeiro momento, com os detalhes neoclássicos, em seguida, por meio do ecletismo e da propagação de estilos variados. A planta da casa brasileira urbana, que até o início do século XIX repetia freqüentemente o mesmo programa, levando o engenheiro Vauthier ${ }^{2}$ a afirmar que aquele que viu uma residência urbana do Brasil viu todas, passou a apresentar uma maior 
variação de cômodos, sendo introduzidas áreas como o hall de distribuição ou o vestíbulo até então não empregados na arquitetura urbana de uso residencial.

O jardim ganhou cada vez mais importância no lote urbano ao se aproximar o fim do século, chegando em alguns casos a circundar a residência, apresentando um traçado de influência inglesa ou francesa e muitas vezes a mistura de plantas de origem européia com plantas nativas. $\mathrm{O}$ palacete ajardinado apresentava, contraditoriamente, algumas características das antigas chácaras - como hortas e pomares -, situando-se, contudo, na área urbana.

A essas transformações na concepção da arquitetura e das áreas ajardinadas, corresponderam mudanças no espaço urbano. Nas cidades mais importantes do país, observou-se o processo de calçamento das ruas e criação de passeios junto às construções ${ }^{3}$. Ainda no século XIX, surgiram lampiões e postes de iluminação nesses espaços públicos e os primeiros exemplares arbóreos alinhados ao longo do calçamento. A rua ganhava status.

Em apenas um século, transformou-se a casa, alterou-se o jardim, modificou-se a rua. Em todos os casos, construções e espaços livres submeteram-se à influência européia.

\section{Transformações na casa e no jardim: do sobrado erguido no alinhamento ao palacete ajardinado}

Em São Paulo, nas primeiras décadas do século XIX, havia casas térreas e sobrados erguidos no alinhamento de ruas estreitas e tortuosas. Eram implantados lado a lado, sem recuo lateral. O lote era estreito e comprido - o "jardim-horta-pomar" ficava ao fundo, no recuo posterior.

Saint-Hilaire, como John Mawe ${ }^{4}$ e outros viajantes europeus, deixou registrada uma descrição minuciosa da casa paulistana das primeiras décadas do século XIX em seus relatos de viagem. Escreveu sobre as casas de taipa, caiadas e cobertas de telhas, que lhe pareceram sem opulência alguma, mas de aspecto vistoso e limpo, com seus beirais a proteger as paredes das águas da chuva ${ }^{5}$.

Daniel Kidder referiu-se à forma de distribuição interna dos cômodos dessas residências - muito semelhante à das casas urbanas de outras regiões do país:

Nas cidades, o andar inferior raramente é ocupado para moradia; serve às vezes para casas de comércio, outras vezes para cocheira ou estábulo. As dependências mais comuns, em cima, são: a sala de visitas e a de jantar, entre as quais existem, invariavelmente, alcovas que servem de dormitórios. ${ }^{6}$ 
O interior das casas térreas e sobrados do Rio de Janeiro foi descrito por Robert Burford, em 1823, que estabeleceu uma diferenciação social entre essas construções - as casas térreas pertencendo às pessoas mais simples, o sobrado sendo destinado às camadas mais ricas da sociedade:

(...) The houses of a single story consist of one good room, floored with boards, with alcoves for sleeping, a kitchen, and an enclosed yard, with stable, \&c. the only passage to which is through the best apartment. The houses of two or three stories for the higher classes, have usually an open space in front, with large folding gates; a broad flight of steps leads to the upper story, consisting of the sala or drawing room, gorgeously painted and gilt, with folding doors leading to the sleeping alcoves, beyond which is the varanda, in which the family generaly take their meals, and receive visits during the day, the lower parts are occupied by the slaves, cattle, and for domestic purposes. ${ }^{7}$

As casas térreas eram compostas, portanto, por sala, alcovas e cozinha; os sobrados seguiam o mesmo esquema no pavimento superior, ficando o térreo para os escravos, animais ou outros propósitos domésticos.

Debret também caracterizou as casas da cidade do Rio de Janeiro em seus escritos, afirmando serem, em geral, estreitas e profundas, com sala de visitas dando para a rua, quartos de dormir situados depois da sala, e um corredor que conduzia à sala de jantar (ou varanda), à cozinha e aos aposentos dos escravos ${ }^{8}$.

Segundo Johann Emmanuel Pohl, eram poucas as casas do Rio de Janeiro que possuíam mais de um andar ${ }^{9}$. O estilo dessas construções era uniforme e, da mesma forma que as casas do subúrbio, as residências urbanas eram construídas de pedra e cobertas de telhas. Para Pohl, essas residências eram "mesquinhas", dando abrigo a dez ou doze pessoas que viviam em pequenas dependências e alcovas ${ }^{10}$.

Spix e Martius observaram que a maioria das casas era feita "com granito miúdo, ou madeira nos pavimentos superiores, e cobertas de telhas". As sacadas, "fechadas e sombrias, à moda oriental", haviam sido "rasgadas em balcões abertos diante das janelas", por ordem superior $^{11}$.

George Gardner, que esteve no Rio de Janeiro em 1837 (mais de dez anos depois da visita de Johann Emmanuel Pohl), fala de "casas edificadas solidamente e na maior parte de pedra", em geral de dois ou três pavimentos ${ }^{12}$. Maria Graham, da mesma forma, fala de "casas de três ou quatro pavimentos, com tetos salientes, toleravelmente belas"13. 
Nas residências urbanas do Recife, Vauthier observou a mesma forma de distribuição interna dos cômodos das casas do Rio de Janeiro e de São Paulo: sala na frente, uma ou duas alcovas e varanda nos fundos - com um corredor ligando a sala à varanda ${ }^{14}$.

Maria Graham, da mesma forma que Vauthier, deixou registradas as características da arquitetura mais antiga do Recife:

(...) As casas são de três ou quatro andares, feitas de pedra clara e são todas caiadas, com as molduras das portas e janelas de pedra parda. $O$ andar térreo consiste em lojas ou alojamentos para negros ou cavalariças, o andar de cima é geralmente adequado para escritórios e armazéns. Os apartamentos para residência são mais acima, ficando a cozinha geralmente no alto. Por este meio a parte inferior da casa conserva-se fresca. $^{15}$

No bairro do Recife, as casas eram "de tijolos, com três, quatro e mesmo cinco andares" - as mais antigas possuindo apenas um andar, ou apenas o térreo ${ }^{16}$. Em Santo Antônio, as ruas eram largas e os edifícios, "muito altos para sua largura", com lojas, armazéns, oficinas e cocheiras no térreo ${ }^{17}$. Os sobrados do Recife eram, em geral, mais altos que os do Rio de Janeiro e São Paulo. Concorriam com eles, em altura, alguns sobrados da Bahia.

Em Salvador, nas proximidades da alfândega e do cais de desembarque, havia sobrados com "três, quatro e mesmo cinco andares", mas não comportavam mais que três ou quatro janelas na fachada ${ }^{18}$. Na cidade baixa, dos altos sobrados, habitavam os comerciantes; os mais ricos possuíam "casas de campo ou chácaras nas colinas, fora do centro da cidade"19.

Spix e Martius escreveram sobre o material construtivo das construções da cidade alta de Salvador, afirmando serem predominantemente de pedra. Parte desses edifícios também apresentava de três a cinco pavimentos ${ }^{20}$.

Desse modo, observa-se que a casa brasileira do século XIX era térrea ou assobradada, com dois, três, quatro e até cinco pavimentos em algumas cidades, configurando por vezes uma paisagem mais vertical que horizontal. A importância do sobrado na paisagem urbana do Brasil foi ressaltada por Gilberto Freyre - quem primeiro elaborou a síntese desse tipo habitacional do início do século XIX: "os do Recife parecendo ter sido os mais altos, e quase sempre, como os da Bahia e do Rio de Janeiro, de pedra ou tijolo; os de São Paulo, de taipa e, na média, de dois pavimentos, os do Rio, de dois e três andares." ${ }^{21}$ Mas sempre a mesma divisão interna dos cômodos: sala na frente, alcova e corredores sombrios, e cozinha nos fundos ${ }^{22}$. 
Nas áreas semi-urbanas, a casa de chácara (ou de campo) era, por sua vez, mais casa de fazenda que de cidade; mais horizontal do que vertical; mais assobradada do que sobrado ${ }^{23}$. E, quase sempre, ajardinada.

Nos arredores de São Paulo, Saint-Hilaire avistou "bonitas casas espalhadas pelo campo" 24 e numerosas chácaras embelezando a paisagem - muitas delas situadas em amplos terrenos cercados, com plantações de cafeeiros, laranjeiras, jabuticabeiras e outras árvores de fruto $^{25}$.

Cabe aqui ressaltar o papel do jardim na qualificação das casas de campo e de chácara. Enquanto as residências urbanas eram erguidas umas ao lado das outras, sem recuo lateral, no alinhamento das ruas, com um "jardim-horta-pomar" atrás dos muros, no recuo posterior, as residências semi-urbanas estavam isoladas no lote e cercadas por áreas ajardinadas. As árvores e flores dessas áreas ajardinadas qualificavam a paisagem e a arquitetura, em consonância com a natureza em derredor.

Assim como em São Paulo, no Rio de Janeiro havia casas de chácara nos bairros mais afastados do centro, com as construções mais amplas, cercadas por jardins: “(...) The houses in the suburbs are large, more convenient, and abound in the comforts of Europe: they are generally in large gardens, which during a great part of the year resemble huge bouquets (...). ${ }^{, 26}$

Saint-Hilaire apresentou uma visão mais crítica em relação às construções dos arredores do Rio de Janeiro, afirmando não terem magnificência alguma e pouco seguirem as regras da arte - não obstante, seu aspecto contribuía "para tornar a paisagem mais pitoresca" 27 .

Maria Graham estabeleceu uma diferenciação entre as casas de campo nas proximidades do bairro das Laranjeiras (casas "nem grandes, nem luxuosas", mas decoradas com varandas e possuindo ao menos uma aléia de flores junto à entrada principal) e as casas de campo na vizinhança do Catete - construídas como as do Sul da Europa, com jardim junto à casa ${ }^{28}$.

Segundo George Gardner, o bairro do Catete, assim como Laranjeiras e Botafogo, era um dos locais favoritos de residência dos europeus, especialmente os ingleses ${ }^{29}$. Sendo habitados por europeus, evidentemente algumas de suas características rememoravam se não a forma de construir, ao menos a forma de implantação da casa européia - cercada por jardins.

Em relação às casas de campo do Recife, situadas nos arredores da cidade, Maria Graham observou que eram "adornadas de pomares e jardins" ${ }^{30}$. Koster denominou essas 
casas de "residências de verão", sendo sua descrição bastante semelhante à elaborada por Maria Graham ${ }^{31}$ : “(...) São pequenas, asseadas e brancas casinhas de andar térreo, com jardins na porta e nos flancos, plantados de laranjeiras, limões, romãs e muitas espécies de árvores de fruto." 32

Em Salvador, as casas ajardinadas ficavam no bairro denominado "Vitória" - o pitoresco e favorito subúrbio da Bahia; local escolhido para implantação das chácaras e residências "quase" de campo, segundo Ouseley ${ }^{33}$, ou das casas-jardim, com suas flores e frutos se derramando sobre a baía, nos dizeres de Maria Graham ${ }^{34}$.

O pintor viajante, Rugendas, também observou em seus escritos que os edifícios da cidade alta, em Salvador, eram cercados de bosques e jardins; vistos do porto, sublinhou, apresentavam um aspecto "bastante pitoresco",35.

Se a princípio o jardim se tornou elemento característico da paisagem das áreas semiurbanas e dos bairros distantes do centro, com as modificações na forma de implantação das construções no lote urbano ao longo do século XIX, as áreas ajardinadas foram conquistando cada vez mais espaço no interior da cidade brasileira.

Uma das primeiras transformações estava relacionada à "libertação das construções em relação aos limites dos lotes". O edifício foi recuado dos limites laterais, conservando-se, no entanto, sobre o alinhamento da via pública. O recuo podia ser de um ou de ambos os lados da construção ${ }^{36}$. Nas residências mais amplas, o jardim lateral foi implantado nesse espaço um elemento paisagístico importante para a melhoria das condições de arejamento e iluminação da arquitetura urbana de uso residencial ${ }^{37}$. Para ligar os jardins à construção, empregou-se um elemento bastante comum à casa brasileira: a varanda - apoiada então em colunas de ferro, com gradis e degraus de mármore na escada ${ }^{38}$.

As residências menores não contavam com jardim lateral, mas apresentavam uma pequena entrada descoberta, com portão e escada de ferro. Em ambos os casos, suprimiram-se as alcovas ${ }^{39}$. A disposição interna dos cômodos era, no entanto, semelhante àquela do período colonial: sala de visitas à frente, quartos em torno de um corredor e cozinha e banheiro ao fundo $^{40}$. As chácaras, situadas nos arredores das cidades, também se transformaram. A área de seus terrenos foi se reduzindo aos poucos e a arquitetura foi assumindo cada vez mais características urbanas ${ }^{41}$.

Nos últimos anos do século XIX, completou-se a "primeira etapa da libertação da arquitetura em relação aos limites dos lotes”, com a introdução do recuo e do jardim frontal. Nesse momento, fundiram-se duas tradições: a das chácaras e a dos sobrados ${ }^{42}$. Muitas vezes, 
entretanto, a arquitetura conservou-se "pesada, calcada ainda no emprego da antiga taipa de pilão, do adobe e da telha canal". Mesmo quando as paredes eram de tijolo, a largura era exagerada $^{43}$. No plano formal, despontava o Ecletismo ${ }^{44}$.

Os jardins da segunda metade do século XIX evidenciavam, da mesma forma que a arquitetura, a influência européia, com suas flores e arbustos dispostos em canteiros de traçado geométrico, protegidos por muretas de tijolo. Quando a construção apresentava detalhes neoclássicos, colocava-se entre as plantas do jardim uma ou outra figura de mármore; quando eclética, era possível encontrar fontes, grutas e lagos artificiais com pontes de cimento que imitavam troncos de madeira em meio às áreas ajardinadas que cercavam a construção. Nas chácaras, eram comuns os mirantes junto aos muros, circundados por grades ou balaustradas e, por vezes, protegidos por pérgulas ${ }^{45}$.

O último passo da libertação da arquitetura em relação aos limites do lote (o isolamento da residência no centro do terreno), com raras exceções, seria uma experiência do século $\mathrm{XX}^{46}$. Esta seria de fato uma das características dos palacetes do ecletismo - "um tipo de casa unifamiliar, de um ou mais andares, com porão, ostentando apuro estilístico, afastada das divisas do lote, de preferência nos quatro lados, situada em meio a jardins, possuindo área de serviços e edículas nos fundos" ${ }^{\star 47}$. Esse tipo de habitação corresponderia ao ápice das transformações da arquitetura, do jardim e do lote urbano que se observaram ao longo do século XIX, quando a arquitetura tradicional foi sobrepujada pelo modelo europeu de habitação.

\section{Transformações na rua}

A rua da cidade brasileira principia o século XIX caracterizada pela irregularidade do traçado, pela falta de alinhamento, pela ausência de calçamento, pela carência de iluminação pública e pela imundície. As águas das chuvas eram despejadas nas ruas pelos telhados e ponteiras das residências; eram despejados também nesse espaço público os detritos orgânicos da casa pelos próprios moradores ou por escravos. A rua era o "escoadouro das águas servidas dos sobrados", nos dizeres de Gilberto Freyre ${ }^{48}$. Atirava-se para o meio da rua o resto de comida, a água servida, o material recolhido nos tigres.

Quando Maria Graham esteve no Brasil, surpreendeu-se com a sujeira de algumas ruas de Salvador: "A rua pela qual entramos através do arsenal ocupa aqui a largura de toda a cidade baixa da Bahia, e é sem nenhuma exceção o lugar mais sujo em que eu tenha estado.”49 
Até então o brasileiro não estivera preocupado com o espaço público. Datam do século XIX algumas das primeiras posturas municipais em defesa da rua, na tentativa de conter os abusos do sobrado. A rua deixa de ser o escoadouro das águas servidas das residências urbanas, "para ganhar em dignidade e em importância social"50.

De fato, ao longo do século XIX muitas mudanças se processaram nesse espaço urbano. As gelosias e janelas que abriam para a rua foram proibidas. Junto às casas, foram instalados lampiões, que foram posteriormente substituídos por postes de iluminação pública independentes das construções. Algumas ruas foram macadamizadas - cobertas com pedra britada; outras foram cobertas com paralelepípedos. Na segunda metade do século, surgiram os trilhos de fenda nessas mesmas ruas, já calçadas, por onde trafegavam os bondes. Ao pedestre foi assegurado o passeio (ainda bastante estreito) junto às residências. Algumas ruas foram alinhadas ou retificadas; novas ruas foram abertas, acompanhando o crescimento das cidades, possuindo largura mais expressiva em relação às antigas vias de circulação. Foram implantados também os primeiros sistemas de distribuição de água e coleta de esgoto. As águas da chuva deixaram de ser despejadas na rua. Mas de todas essas mudanças - algumas de ordem estética, outras resultantes de necessidades prementes - uma demonstrou uma preocupação maior com o meio ambiente urbano: a arborização das ruas.

O plantio de árvores ao longo do calçamento não resultava apenas de uma intenção estética - embora seja evidente a influência européia nesse processo. Em algumas cidades do Nordeste e do Norte do país, o poder municipal chegou a adotar árvores nativas na arborização urbana $^{51}$. Ainda que a questão ambiental tenha surgido entre nós apenas no século XX, há indícios de uma certa preocupação com o meio ambiente no século XIX, como demonstram não apenas o emprego de espécies nativas na arborização urbana, mas o reflorestamento de algumas áreas, como a Tijuca, no Rio de Janeiro.

A arborização urbana corresponde talvez ao ponto mais alto de valorização da rua sanadas as necessidades (calçamento, iluminação, água e esgoto), passou-se à valorização do lugar com o plantio de exemplares arbóreos. A introdução do jardim lateral e frontal no lote urbano de uso residencial iria corroborar a valorização da rua, do espaço público urbano.

Ao findar o século XIX, a rua brasileira - ou pelo menos as de maior importância era calçada, iluminada, percorrida pelos bondes, por vezes arborizada e ladeada por casas com jardim. Uma outra rua, a conformar uma nova paisagem. 


\section{Conclusão}

No Brasil, o século XIX correspondeu a uma série de transformações na arquitetura de uso residencial, no jardim junto à residência, e na rua. Em apenas um século, a construção urbana erguida no alinhamento, sem recuo lateral, em lotes estreitos e compridos, com jardim ao fundo, passou a ser construída recuada em relação aos limites do lote, com jardim frontal ou lateral. Na fachada, foram banidos elementos como muxarabis e gelosias, difundindo-se o emprego do vidro. Sobre as paredes de pedra ou de taipa foram colocados detalhes ornamentais de cunho neoclássico. Posteriormente, propagou-se o Ecletismo nas construções de tijolo, com um novo programa de necessidades, de nítida influência européia. Da mesma forma o jardim recebeu as influências externas, assumindo características francesas ou inglesas, com um traçado geométrico ou sinuoso.

$\mathrm{Na}$ área urbana, as ruas foram calçadas, difundindo-se também o passeio junto às construções. Propagaram-se a iluminação pública e os sistemas de distribuição de água e coleta de esgoto. Surgiram as primeiras tentativas de arborização urbana. As novas ruas foram projetadas com maior largura e melhor alinhamento.

Mudaram a rua, a construção e o jardim. Transformou-se a paisagem.

O espaço urbano tradicional foi europeizado tanto no âmbito privado como no âmbito público, configurando-se um novo cenário para a cidade brasileira.

1. FREYRE, Gilberto. Sobrados e mucambos. 16.ed. São Paulo: Global, 2006, p. 254.

2. VAUTHIER, L. L. "Casas de residência no Brasil". In: Arquitetura civil I. São Paulo: FAUUSP: MECIPHAN, 1975, p.37.

3. REIS FILHO. Nestor Goulart. Quadro da arquitetura no Brasil. São Paulo: Perspectiva, 1970, p.42.

4. MAWE, John. Viagens ao interior do Brasil. Trad. Selena Benevides Viana. São Paulo: Edusp, 1978, p.63-4.

5. SAINT-HILAIRE, Auguste de. Viagem à província de São Paulo. Trad. Regina Regis Junqueira. Sâo Paulo: Edusp, 1976, p.128.

6. KIDDER, Daniel. Reminiscências de viagens e permanências nas províncias do Sul do Brasil: Rio de Janeiro e província de São Paulo. São Paulo: Edusp, 1980, p.206-7.

7. "As casas térreas possuem uma boa sala assoalhada, com alcovas, uma cozinha e um pátio fechado com estábulo, ao qual se tem acesso por meio dos cômodos principais. Os sobrados de dois ou três pavimentos destinados às classes mais ricas comumente possuem um espaço livre frontal cercado por grades; um amplo lance de escadas leva ao pavimento superior composto por uma sala agradavelmente pintada e dourada, com 
portas que levam para as alcovas de dormir, além das quais se situa a varanda onde a família geralmente faz suas refeições e recebe visitas durante o dia; a parte mais baixa da construção é ocupada pelos escravos, por animais ou destinada a fins domésticos." BUFFORD, Robert. Description of a view of the city of St. Sebastian, and bay of Rio de Janeiro (1823). London: J. And C. Adlard, Bartholomew Close, 1827, p.7. (Tradução da autora)

8. DEBRET, Jean Baptiste. Viagem pitoresca e histórica ao Brasil (1768-1848). Trad. Sérgio Milliet. São Paulo: Edusp, 1978, p.306.

9. POHL, João Emanuel. Viagem ao interior do Brasil. Trad. Milton Amado. São Paulo: Edusp, 1976 p.38.

10. Idem, ibid., p.39.

11. SPIX, Johann Baptiste von \& MARTIUS, Carl Friedrich Philipp von. Viagem pelo Brasil: 1817-1820. São Paulo: Melhoramentos, 1968, p.18.

12. GARDNER, George. Viagem ao interior do Brasil. Trad. Milton Amado. São Paulo: Edusp, 1975, p.21.

13. GRAHAM, Maria. Diário de uma viagem ao Brasil e de uma estada nesse país durante parte dos anos de 1821, 1822 e 1823. São Paulo: Edusp, 1990, p.207.

14. VAUTHIER, Op. cit., p.37-9.

15. GRAHAM, Op. cit., p.132.

16. KOSTER, Henry. Viagens ao Nordeste do Brasil. Trad. Luiz da Câmara Cascudo. São Paulo: Companhia Editora Nacional, 1942, p.34.

17. Idem, ibid., p.35.

18. RUGENDAS, João Maurício. Viagem pitoresca através do Brasil. São Paulo: Círculo do Livro, s.d., p.75.

19. Idem, ibid., p.75.

20. SPIX \& MARTIUS, Op. cit., p.157.

21. FREYRE, Op. cit., p.309.

22. Idem, ibid., p.327.

23. Idem, ibid., p.323.

24. SAINT-HILAIRE, Op. cit., p.127.

25. Idem, ibid., p.148

26. "As construções nos arredores da cidade são amplas, mais convenientes, e possuem muitos dos confortos da Europa: geralmente estão circundadas por vastos jardins, os quais, durante a maior parte do ano, parecem um frondoso buquê.” BURFORD, Op. cit., p.7. (Tradução da autora)

27. SAINT-HILAIRE, Op. cit., p.35.

28. GRAHAM, Op. cit., p.198.

29. GARDNER, Op. cit., p.22.

30. GRAHAM, Op. cit., p.145.

31. Idem, ibid., p.160.

32. KOSTER, Op. cit., p.43.

33. OUSELEY, W. M. Gore. Description of views in South America. London: Thomas Mc Lean, 1852, p.13.

34. GRAHAM, Op. cit., p.166.

35. RUGENDAS, Op. cit., p.74.

36. REIS FILHO, Op. cit., p.44.

37. Idem, ibid., p.46.

38. Idem, ibid., p.46.

39. Idem, ibid., p.46.

40. Idem, ibid., p.46.

41. Idem, ibid., p.48.

42. Idem, ibid., p.50-2.

43. Idem, ibid., p.52.

44. Idem, ibid., p.154.

45. Idem, ibid., p.172.

46. Idem, ibid., p.173.

47. NACLÉRIO HOMEM, Maria Cecília. O palacete paulistano e outras formas urbanas de morar da elite cafeeira (1867-1918). São Paulo: Martins Fontes, 1996, p.14.

48. FREYRE, Op. cit., p.32.

49. GRAHAM, Op. cit., p.145.

50. FREYRE, Op. cit., p.32-3.

51. Em nota ao texto de Vauthier (1975, p.36), Gilberto Freyre assinala: "O serviço de arborização do Recife seria intensificado em 1857. As árvores então plantadas, informa Pereira da Costa nos seus referidos MSS, que foram 'o castanheiro do Pará e a gameleira, ainda restando desta uma belíssima que se vê na Praça da República junto à entrada da Ponte de Santa Isabel' (o cronista escrevia nos fins do século passado)." Datam de meados do século XIX algumas das primeiras iniciativas de arborização urbana no Brasil. Nas fotografias da segunda 
metade do oitocentismo aparecem ruas com exemplares arbóreos ao longo do passeio ou mesmo do leito carroçável - como a ladeira de São Bento em Salvador.

* Artigo recebido em agosto de 2008. Aprovado em novembro de 2008. 